\title{
Oncologist
}

\section{The Outcomes and Safety of Single-Agent Sorafenib in the Treatment of Elderly Patients with Advanced Hepatocellular Carcinoma (HCC)}

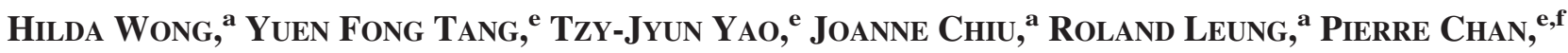 \\ Tan To Cheung, ${ }^{b}$ Albert C. Chan, ${ }^{b}$ Roberta W. Pang,,${ }^{b, c}$ Ronnie Poon, ${ }^{b, c, d}$ Sheung-Tat Fan, ${ }^{b, c, d}$ \\ ThOMAS YAU ${ }^{\mathbf{a}, \mathbf{b}, \mathbf{c}}$
}

${ }^{\mathrm{a}}$ Department of Medicine and ${ }^{\mathrm{b}}$ Department of Surgery, Queen Mary Hospital, Hong Kong; ${ }^{\mathrm{c} C e n t r e}$ for Cancer Research, ${ }^{\mathrm{d}}$ State Key Laboratory of Liver Diseases, and ${ }^{\mathrm{e}}$ Clinical Trial Center, The University of Hong Kong,

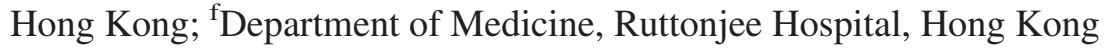

Key Words. Sorafenib • Elderly • Advanced HCC

Disclosures: Hilda Wong: None; Yuen Fong Tang: None; Tzy-Jyun Yao: None; Joanne Chiu: None; Roland Leung: None; Pierre Chan: None; Tan To Cheung: None; Albert C. Chan: None; Roberta W. Pang: None; Ronnie Poon: Bayer Pharmaceuticals Limited (RF); Sheung-Tat Fan: None; Thomas Yau: Bayer Schering (C/A).

(C/A) Consulting/advisory relationship; (RF) Research funding; (E) Employment; (H) Honoraria received; (OI) Ownership interests; (IP) Intellectual property rights/inventor/patent holder

\begin{abstract}
Background. With the aging population, hepatocellular carcinoma (HCC) in the elderly represents a significant health burden. We aimed to evaluate and compare the efficacy and tolerability of single-agent sorafenib in treating elderly patients with advanced HCC versus the younger population.

Methods. We retrospectively analyzed a consecutive cohort of advanced HCC patients with Child-Pugh A or B liver function and an Eastern Cooperative Oncology Group performance status score of $0-2$ treated with sorafenib. The patients were categorized into older (age $\geq 70$ years) and younger (age $<70$ years) groups. Treatment outcomes and related adverse events (AEs) were compared.

Results. In total, 172 patients, 35 in the older (median age, 73 years) and 137 in the younger (median age, 55
\end{abstract}

years) group, were analyzed. The median progressionfree survival time was similar in the older and younger groups (2.99 months versus 3.09 months; $p=.275)$, as was the overall survival time (5.32 months versus 5.16 months; $p=.310$ ). Grade 3 or 4 AEs were observed in $68.6 \%$ of older and $62.7 \%$ of younger patients $(p=.560)$, with neutropenia $(11.4 \%$ versus $0.7 \% ; p=.007)$, malaise $(11.4 \%$ versus $2.2 \% ; p=.033)$, and mucositis $(5.7 \%$ versus $0.0 \% ; p=.041)$ being more frequently reported in the elderly cohort.

Conclusions. The survival benefits and overall treatmentrelated AEs of sorafenib are comparable in elderly and younger advanced HCC patients. Nevertheless, more vigilant monitoring in the elderly is warranted because they are more susceptible to develop neutropenia, malaise, and mucositis. The Oncologist 2011;16:1721-1728

\section{BACKGROUND}

Hepatocellular carcinoma (HCC) is the fifth most common cancer in men and seventh in women worldwide; it is also the third most common cause of cancer mortality [1]. The majority of cases occur in developing countries, especially Asia [1], where hepatitis B infection is endemic, whereas in recent years both the incidence and mortality rates of HCC have increased 
in western countries as a result of hepatitis $\mathrm{C}$ infection and alcoholic cirrhosis [2].

Cancer risk rises steeply with advancing age [2]. As with other common cancers, the development of HCC is age dependent [3] In particular, in compensated viral cirrhotic patients, advanced age, representing longer duration of infection, is an independent risk factor [4]. With the aging population, HCC diagnosed in elderly patients will increasingly become a significant global health issue.

Elderly cancer patients often have medical comorbidities and altered drug pharmacokinetics, impaired organ function, reduced functional status, and more tumor symptoms [5]. Systemic treatment is frequently either modified or withheld in the management of elderly patients for fear of their poor tolerance of potential toxicities [6]. When given, its therapeutic benefit and toxicity profile are largely unclear because elderly patients have generally been underrepresented in clinical trials [7]. Although recent trends for greater older patient enrollment have been observed, the proportion of these patients continues to be lower than expected in study populations [8]. Increasing awareness of the problem has led to studies dedicated to elderly patients, but accrual is difficult and data remain limited.

Historically, elderly patients with HCC were investigated less intensively and treated more conservatively despite similar tumor stages at diagnosis, leading to significantly worse survival outcomes [9]. On the other hand, $\mathrm{HCC}$ in elderly patients may have a more favorable tumor biology than in younger patients. A recent study involving, specifically, hepatitis C infection-related HCC patients showed that elderly patients, in general, presented with more favorable tumor characteristics and had a better overall prognosis [10]. In the literature, there is only a paucity of data regarding the optimal management of elderly HCC patients. Although age did not seem to influence treatment options or preclude patients from treatment [10-12], most studies included heterogeneous cohorts with variable underlying liver function and tumor stages. Those studies were also performed prior to the era of sorafenib, which is now the recommended treatment for advanced HCC [13]. Specifically, treatment outcomes with sorafenib in elderly advanced HCC patients are not known yet. In this study, we evaluated and compared the efficacy and tolerability of sorafenib between younger $(<70$ years old) and older $(\geq 70$ years old) patients with advanced HCC not amenable to locoregional therapy or surgical interventions.

\section{Methods}

\section{Patients}

We retrospectively analyzed a consecutive cohort of advanced HCC patients treated with sorafenib between November 2006 and October 2010 in a single tertiary referral center in Hong Kong. Data were retrieved from a prospectively maintained database as part of a study approved by the Ethic Committee of Queen Mary Hospital, The University of Hong Kong. Moreover, data from elderly patients with advanced HCC not amenable to surgical interventions and local ablative therapies who did not receive sorafenib treatment during the same time period were also analyzed.

The diagnosis of HCC was made by either histology or cytology, or by elevated $\alpha$-fetoprotein (AFP) ( $\geq 400 \mathrm{ng} / \mathrm{mL}$ ) with typical radiological appearance according to the European Association for the Study of the Liver criteria [14]. All patients were confirmed inoperable and/or unsuitable for local ablative therapy or surgical interventions after staging assessment by computed tomography (CT) or positron emission tomography (PET)-CT. Patients with underlying liver cirrhosis of ChildPugh class $\mathrm{C}$ or a baseline Eastern Cooperative Oncology Group (ECOG) performance status score $\geq 3$ were excluded from the analysis.

\section{Response and Adverse Events}

Patients were treated with single-agent sorafenib, $400 \mathrm{mg}$ twice daily orally, with prior informed consent. Dosage reductions were allowed on occurrence of adverse events (AEs) of grade $\geq 3$ as graded by the National Cancer Institute Common Terminology Criteria for Adverse Events, version 3.0. Treatment was continued until disease progression or unacceptable toxicities. Tumor assessments were performed by CT, PET$\mathrm{CT}$, or magnetic resonance imaging at baseline then every 2-3 months. All radiological assessments were performed by core designated radiologists at Queen Mary Hospital, The University of Hong Kong. Hematological parameters, blood biochemistry, and AFP levels were also monitored every 3-4 weeks, or more frequently if needed. Response was defined according to the Response Evaluation Criteria in Solid Tumors 1.0 [15] as complete response (CR), partial response (PR), stable disease (SD), and progressive disease. The disease control rate (DCR) was defined as the sum of the proportion of patients with CR, PR, and SD.

\section{Statistical Analysis}

All statistical analyses were performed using the SAS ${ }^{\circledR}$ software, version 9.1.3 (SAS Institute, Cary, NC), and R version 2.10.1. Categorical data were compared using Fisher's exact test. The duration of treatment was measured from the date of treatment commencement until termination or last follow-up, including times of interruptions, and summarized using the Kaplan-Meier method. The follow-up time was also summarized using the KaplanMeier method treating time of death as the censored follow-up time. The progression-free survival (PFS) time was measured from the date of treatment commencement until disease progression or last follow-up. The overall survival (OS) time was measured from the date of treatment commencement to the date of death or last follow-up. Both the PFS and OS times were estimated using the Kaplan-Meier method and were compared using the log-rank test. Associations between selected risk factors and the OS or PFS times were tested univariately using Cox proportional hazards regression [16]; factors entered for analysis included age, gender, hepatitis B and C status, antiviral treatment, AFP level, Child-Pugh class, ECOG performance status score, Barcelona Clinic Liver Cancer stage, diabetes, and cardiovascular comorbidities, including hypertension. Age group and all factors with a $p$-value $<.1$ on univariate analysis were included in the 
Table 1. Demographic characteristics of younger and elderly hepatocellular carcinoma patients who received sorafenib

\begin{tabular}{|c|c|c|c|c|}
\hline Patient characteristics & $\begin{array}{l}\text { All patients } \\
(n=172)\end{array}$ & $\begin{array}{l}\text { Age }<70 \text { yrs } \\
(n=137,79.7 \%)\end{array}$ & $\begin{array}{l}\text { Age } \geq 70 \text { yrs } \\
(n=35,20.3 \%)\end{array}$ & $p$-value \\
\hline Median age (range), yrs & $57.5(19-85)$ & $55(19-69)$ & $73(70-85)$ & \\
\hline Gender & & & & .014 \\
\hline Male & $147(85.5 \%)$ & $122(89.1 \%)$ & $25(71.4 \%)$ & \\
\hline Female & $25(14.5 \%)$ & $15(10.9 \%)$ & $10(28.6 \%)$ & \\
\hline \multicolumn{5}{|l|}{ Viral hepatitis status } \\
\hline HBV positive & $148(86.1 \%)$ & $125(91.2 \%)$ & $23(65.7 \%)$ & $<.001$ \\
\hline On antiviral treatment & $81(47.1 \%)$ & $68(54.4 \%)$ & $13(56.5 \%)$ & \\
\hline HCV positive & $11(6.4 \%)$ & $7(5.1 \%)$ & $4(11.4 \%)$ & .237 \\
\hline AFP, ng/mL & & & & .573 \\
\hline$<400$ & $76(44.2 \%)$ & $59(43.1 \%)$ & $17(48.6 \%)$ & \\
\hline$\geq 400$ & $96(55.8 \%)$ & $78(56.9 \%)$ & $18(51.4 \%)$ & \\
\hline Child-Pugh class & & & & 1.000 \\
\hline A & $108(62.8 \%)$ & $86(62.8 \%)$ & $22(62.9 \%)$ & \\
\hline B & $64(37.2 \%)$ & $51(37.2 \%)$ & $13(37.1 \%)$ & \\
\hline ECOG performance status score $(n=171)$ & & & & .094 \\
\hline 0 & $55(32.2 \%)$ & $46(33.8 \%)$ & $9(25.7 \%)$ & \\
\hline 1 & $105(61.4 \%)$ & $84(61.8 \%)$ & $21(60.0 \%)$ & \\
\hline 2 & $11(6.4 \%)$ & $6(4.4 \%)$ & $5(14.3 \%)$ & \\
\hline BCLC stage & & & & .697 \\
\hline $\mathrm{B}$ & $11(6.4 \%)$ & $8(5.8 \%)$ & $3(8.6 \%)$ & \\
\hline $\mathrm{C}$ & $161(93.6 \%)$ & $129(94.2 \%)$ & $32(91.4 \%)$ & \\
\hline \multicolumn{5}{|l|}{ Comorbid conditions } \\
\hline Cardiovascular conditions including hypertension & $51(29.7 \%)$ & $35(25.6 \%)$ & $16(45.7 \%)$ & .024 \\
\hline Respiratory disease & $1(0.6 \%)$ & $1(0.7 \%)$ & $0(0 \%)$ & 1.000 \\
\hline Diabetes mellitus & $29(16.9 \%)$ & $18(13.1 \%)$ & $11(31.4 \%)$ & .020 \\
\hline
\end{tabular}

multivariate Cox proportional hazards regression models to study the effect of age group adjusting for other risk factors. All $p$-values resulted from the use of two-sided statistical tests without adjustment for multiple testing. The proportional hazards assumption was assessed by a test based on scaled Schoenfeld residuals [17]. If the assumption did not hold for a factor, a stratified proportional hazards model [18] was further fitted to confirm the effect of age group.

\section{RESUlts}

\section{Patient Demographics}

In total, 172 Child-Pugh class A or class B patients with an ECOG performance status score of $0-2$ received sorafenib for advanced HCC during the period; 137 (79.7\%) belonged to the younger group (age $<70$ years) and $35(20.3 \%$ ) belonged to the older group (age $\geq 70$ years). The median ages were 55 years and 73 years, respectively (Table 1). Most patients were male (89.1\% and $71.4 \%$ in the younger and older groups, respectively), consistent with the local epidemiology. The majority of patients in both groups had reasonable liver function prior to treatment; $62.8 \%$ of patients in the younger group and $62.9 \%$ of patients in the older group had Child-Pugh class A disease $(p=1.000)$. Most patients had an ECOG performance status score of 1 in both age groups, although more elderly patients than younger patients had a performance status score of 2 (Table 1). Disease stage and viral hepatitis $\mathrm{C}$ status were also similar between younger and older patients. However, a significantly higher proportion of younger patients were chronic hepatitis B carriers $(91.2 \%$ of the younger group and $65.7 \%$ of the older group; $p<.001$ ), reflecting the difference in etiology of HCC in these age groups. On the other hand, older patients were more frequently affected by comorbid cardiovascular conditions, including hypertension $(45.7 \%$ versus $25.6 \% ; p=.024)$ as well as diabetes mellitus (31.4\% versus $13.1 \% ; p=.020)$.

During the same time period, 33 elderly HCC patients who had advanced disease not amenable to surgical intervention or local ablative procedures did not receive sorafenib treatment for the following reasons: eight patients were recruited in our 
Table 2. Clinical outcomes of advanced hepatocellular carcinoma patients who received sorafenib

\begin{tabular}{lll}
\hline & $\begin{array}{l}\text { Age }<\mathbf{7 0} \text { yrs } \\
(\boldsymbol{n}=\mathbf{1 3 7 , 7 9 . 7 \%})\end{array}$ & $\begin{array}{l}\text { Age } \mathbf{2 7 0} \text { yrs } \\
(\boldsymbol{n}=\mathbf{3 5 , 2 0 . 3 \%})\end{array}$ \\
\hline Response & $0(0 \%)$ & $0(0 \%)$ \\
$\quad$ Complete remission & $4(2.9 \%)$ & $2(5.7 \%)$ \\
$\quad$ Partial response & $30(21.9 \%)$ & $3(8.6 \%)$ \\
$\quad$ Stable disease & $34(24.8 \%)$ & $5(14.3 \%)$ \\
$\quad$ Disease control rate & $103(75.2 \%)$ & $30(85.7 \%)$ \\
$\quad$ Progressive disease and unavailable response & & \\
Survival, median $(95 \%$ CI), mos & $3.09(2.76-3.42)$ & $2.99(2.30-4.53)$ \\
$\quad$ Progression-free survival & $5.16(4.21-6.05)$ & $5.32(4.44-10.35)$ \\
$\quad$ Overall survival & & .258 \\
\hline Abbreviation: CI, confidence interval. & & .310 \\
\hline
\end{tabular}
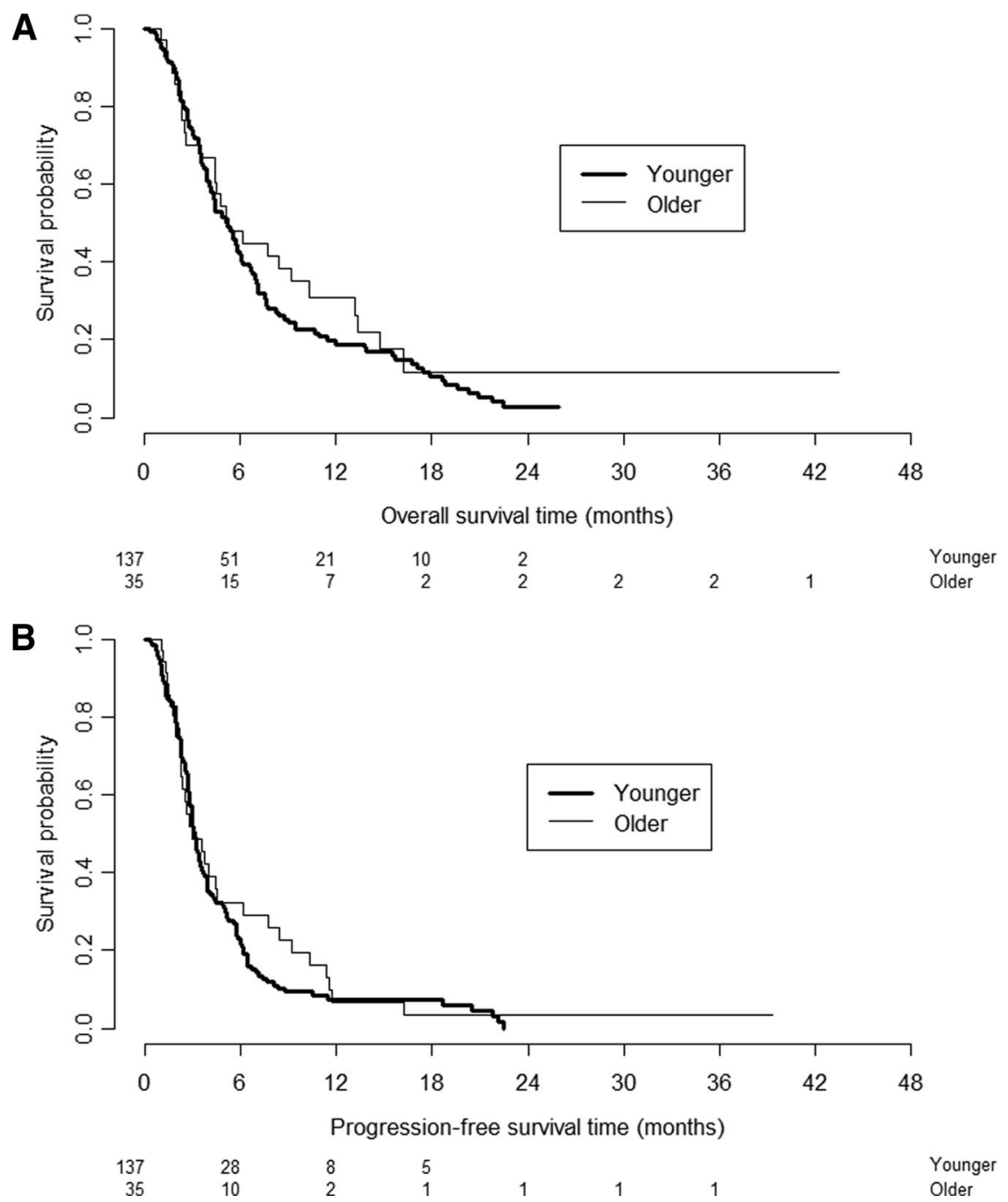

Figure 1. Kaplan-Meier curves for advanced hepatocellular carcinoma patients who received sorafenib, stratified by age groups: (A) Overall survival; (B) Progression-free survival.

systemic therapy clinical trials for advanced HCC and 14 patients refused to take sorafenib, mainly because of the fear of treatment-related toxicities. Nine patients were advised to not take sorafenib because of a poor performance status score 
Table 3. Cox proportional hazards multivariate regression analysis for OS and PFS

\begin{tabular}{|c|c|c|c|c|c|c|}
\hline & \multicolumn{3}{|c|}{ OS } & \multicolumn{3}{|c|}{ PFS } \\
\hline & Hazard ratio & $(95.0 \% \mathrm{CI})$ & $p$-value & Hazard ratio & $(95.0 \% \mathrm{CI})$ & $p$-value \\
\hline Age $\geq 70$ yrs & 0.814 & $(0.520-1.275)$ & .369 & 0.884 & $(0.590-1.326)$ & .552 \\
\hline $\mathrm{HCV}$ positive & - & - & - & 0.537 & $(0.253-1.137)$ & .104 \\
\hline $\mathrm{AFP} \geq 400 \mathrm{ng} / \mathrm{mL}$ & 1.635 & $(1.149-2.328)$ & .006 & 1.262 & $(0.908-1.755)$ & .166 \\
\hline Child-Pugh class B & 1.481 & $(1.051-2.087)$ & .025 & - & - & - \\
\hline ECOG performance status score $1-2$ & 1.812 & $(1.204-2.728)$ & .004 & 1.412 & $(0.997-2.001)$ & .052 \\
\hline BCLC stage $\mathrm{C}$ & 1.378 & $(0.626-3.037)$ & .426 & - & - & - \\
\hline $\begin{array}{l}\text { Cardiovascular conditions including } \\
\text { hypertension }\end{array}$ & 0.713 & $(0.478-1.063)$ & .097 & 0.548 & $(0.374-0.804)$ & .002 \\
\hline
\end{tabular}

(ECOG 3-4) and significant comorbid diseases. Likewise, two patients did not receive sorafenib because of underlying ChildPugh C cirrhosis.

\section{Efficacy and Survival}

The median durations of sorafenib treatment were 2.73 months (95\% confidence interval [CI], 2.37-2.99 months) and 2.32 months (95\% CI, 1.97-2.83 months), respectively, in younger and elderly patients $(p=.830)$. As illustrated in Table 2 , the response rate was $2.9 \%$ in the younger group and $5.7 \%$ in the older group $(p=.603)$; the DCRs were also similar $(24.8 \%$ versus $14.3 \%$, respectively; $p=.258$ ). At median follow-up times of 25.07 months (95\% CI, 21.09-25.99 months) in the younger group and 15.44 months (95\% CI, 9.66-43.50 months) in the older group, the median PFS times were 3.09 months (95\% CI, 2.76-3.42 months) in the younger group and 2.99 months (95\% CI, 2.30-4.53 months) in the older group $(p=.275)$. The median OS times were also comparable at 5.16 months (95\% CI, 4.21-6.05 months) and 5.32 months (95\% CI, 4.44-10.35 months) in the younger and older groups, respectively $(p=.310)$ (Fig. 1).

Table 3 shows the results of multivariate Cox proportional hazards regression analyses of independent prognosticators predicting PFS and OS. Age group did not have a significant effect on either the OS time or the PFS time after adjusting for other risk factors $(p=.369$ and $p=.552$ for the OS and PFS times, respectively).

\section{AEs and Dose Interruption}

The most common nonhematological sorafenib-induced AEs of all grades were diarrhea, malaise, hand-foot syndrome, and hypertension. Grade 3 or 4 AEs were observed in $68.6 \%$ of the older group and in $62.7 \%$ of the younger group $(p=.560)$, with neutropenia $(11.4 \%$ versus $0.7 \% ; p=.007)$, malaise $(11.4 \%$ versus $2.2 \% ; p=.033)$, and mucositis $(5.7 \%$ versus $0 \% ; p=$ .041) being significantly more frequent in the elderly group (Table 4). Interestingly, the observed proportion of patients with sorafenib-related grade 3 or 4 hypertension was larger in elderly patients $(8.6 \%)$ than in younger patients $(2.2 \%)$, and the incidence of grade 3 or 4 gastrointestinal bleeding was lower in elderly patients $(2.9 \%)$ than in younger patients $(11.0 \%)$, but neither difference was significant statistically ( $p=.100$ and $p=.199$, respectively). Also, the proportions of other AEs did not differ significantly with age. Dosage interruption resulting from AEs was observed in 27.8\% and $42.9 \%$ of younger and older patients, respectively, although no statistically significant difference was found $(p=.102)$.

\section{Discussion}

To date, little evidence regarding the efficacy and safety of treating elderly patients with advanced HCC exists in the literature; the present study is the first addressing this pressing issue. The DCR, OS, and PFS outcomes were all similar in the younger and older patient groups. Specifically, there was no significant evidence that age was a factor affecting survival after adjusting for other prognostic factors. Although more AEs were observed in older patients, these were largely manageable and no unexpected toxicities attributable to age were noted. Importantly, the proportion of patients with treatment discontinuation resulting from AEs and their treatment duration remained comparable regardless of age.

These findings are largely concordant with published data on elderly patients receiving systemic therapy for other common types of advanced cancers. In addition to the multitude of studies showing activity for various chemotherapeutic agents in elderly patients with breast cancer [19-23] and non-small cell lung cancer [24-26], comparison of older and younger age groups did not reveal any differences in response or survival, although toxicities were more common in the former [27, 28]. Moreover, a few targeted agents, with their attractive safety profile relative to cytotoxics, have also been evaluated in the elderly. Although the addition of bevacizumab to chemotherapy did not result in a significantly longer survival time in elderly lung cancer patients [29], gefitinib [30] and erlotinib [31, $32]$ in epidermal growth factor receptor mutation-unselected patients in this age group had promising efficacy, at the expense of more, but acceptable, toxicities than in younger patients [31]. For renal cell carcinoma, sorafenib treatment 
Table 4. Sorafenib-related adverse events according to age group

\begin{tabular}{|c|c|c|c|c|c|c|}
\hline & \multicolumn{2}{|c|}{$\begin{array}{c}\text { Age }<70 \text { yrs } \\
(n=137,79.7 \%)\end{array}$} & \multicolumn{2}{|c|}{$\begin{array}{c}\text { Age } \geq 70 \text { yrs } \\
(n=35,20.3 \%)\end{array}$} & \multicolumn{2}{|c|}{$p$-value } \\
\hline & All grade & Grade 3 or 4 & All grade & Grade 3 or 4 & All grade & Grade 3 or 4 \\
\hline Any grade 3 or 4 toxicity $^{\mathrm{a}}$ & & $84(62.7 \%)$ & & $24(68.6 \%)$ & & .560 \\
\hline \multicolumn{7}{|l|}{ Nonhematological } \\
\hline Malaise $^{\mathrm{b}}$ & $49(36.0 \%)$ & $3(2.2 \%)$ & $10(28.6 \%)$ & $4(11.4 \%)$ & .434 & .033 \\
\hline Diarrheab $^{\mathrm{b}}$ & $76(55.9 \%)$ & $13(9.6 \%)$ & $18(51.4 \%)$ & $4(11.4 \%)$ & .705 & .754 \\
\hline Hand-foot skin reaction ${ }^{\mathrm{b}}$ & $56(41.2 \%)$ & $19(14.0 \%)$ & $13(37.1 \%)$ & $4(11.4 \%)$ & .704 & 1.000 \\
\hline $\operatorname{Rash}^{\mathrm{b}}$ & $37(27.2 \%)$ & $10(7.4 \%)$ & $4(11.4 \%)$ & $2(5.7 \%)$ & .074 & 1.000 \\
\hline Hypertension & $32(23.4 \%)$ & $3(2.2 \%)$ & $10(28.6 \%)$ & $3(8.6 \%)$ & .515 & .100 \\
\hline Nausea $^{\mathrm{b}}$ & $12(8.8 \%)$ & $0(0 \%)$ & $1(2.9 \%)$ & $1(2.9 \%)$ & .472 & .205 \\
\hline Mucositis $^{b}$ & $10(7.4 \%)$ & $0(0 \%)$ & $5(14.3 \%)$ & $2(5.7 \%)$ & .194 & .041 \\
\hline Vomiting $^{\mathrm{b}}$ & $6(4.4 \%)$ & $1(0.7 \%)$ & $2(5.7 \%)$ & $1(2.9 \%)$ & .667 & .368 \\
\hline Gastrointestinal bleeding & $15(11.0 \%)$ & $15(11.0 \%)$ & $1(2.9 \%)$ & $1(2.9 \%)$ & .199 & .199 \\
\hline \multicolumn{7}{|l|}{ Hematological } \\
\hline Thrombocytopenia ${ }^{c}$ & $92(68.2 \%)$ & $5(3.7 \%)$ & $29(82.9 \%)$ & $4(11.4 \%)$ & .098 & .088 \\
\hline Leukopenia $^{c}$ & $41(30.4 \%)$ & $2(1.5 \%)$ & $11(31.4 \%)$ & $3(8.6 \%)$ & 1.000 & .060 \\
\hline Anemia $^{c}$ & $78(57.8 \%)$ & $13(9.6 \%)$ & $21(60.0 \%)$ & $2(5.7 \%)$ & .850 & .739 \\
\hline Neutropenia $^{c}$ & $21(15.6 \%)$ & $1(0.7 \%)$ & $8(22.9 \%)$ & $4(11.4 \%)$ & .318 & .007 \\
\hline \multicolumn{7}{|l|}{ Biochemistry } \\
\hline Alanine transaminase ${ }^{c}$ & $98(72.6 \%)$ & $17(12.6 \%)$ & $17(48.6 \%)$ & $4(11.4 \%)$ & .009 & 1.000 \\
\hline Bilirubin $^{c}$ & $96(71.1 \%)$ & $37(27.4 \%)$ & $26(74.3 \%)$ & $7(20.0 \%)$ & .834 & .516 \\
\hline
\end{tabular}

resulted in similar outcomes and manageable toxicities in both age groups [33]. These studies, together with our findings, suggest that elderly cancer patients otherwise eligible should not be precluded from systemic treatment solely based on age. On the other hand, aged patients enrolled in these studies likely represent a fit selected population and results should not be generalized.

Hypertension is one of the most prevalent comorbidities in the elderly, affecting three quarters of patients aged $\geq 70$ years [34]. It is also a common AE observed with sorafenib use, occurring as early as the first day of treatment [35]. It is recognized that elevated blood pressure in elderly patients is mainly caused by an age-related reduction in aortic distensibility [36, 37]. On the other hand, different mechanisms account for sorafenib-induced hypertension; these may include inhibition of endothelial-derived vasodilatory factors such as nitric oxide and endothelial cell apoptosis leading to capillary rarefaction and increased afterload [38]. The effect on blood pressure with a combination of these pathophysiological mechanisms in the elderly may be unpredictable. Moreover, age and hypertension predispose these patients to various cardiovascular events, such as myocardial infarction and ventricular dysfunction, which may also occur rarely with sorafenib treatment [39]. These cardiovascular risks therefore represent a distinct con- cern when treating elderly patients using sorafenib. In our cohort, although pre-existing hypertension and cardiovascular conditions were significantly more common in the elderly group, the requirements for additional antihypertensive intervention (or defined as grade 3) were similar. Life-threatening complications, such as hypertensive crisis, and other cardiovascular events were not observed in either age group. These findings are consistent with other studies showing that, in patients on sorafenib, there is no correlation between age and variability in blood pressure [35], and that cardiovascular events are not only comparable between age groups but are also rare [33].

Apart from hypertension and cardiovascular conditions, elderly people have a higher risk for bleeding and thrombosis [40], also known complications associated with angiogenic inhibitors, including sorafenib [39]. Our results and others (in non-small cell lung cancer [41] and renal cell carcinoma [33] patients) showed that age did not affect the incidence of such complications in patients on these targeted agents.

Interestingly, in contrast to the popular concern of lesser efficacy and poorer safety with sorafenib use in the elderly, it has been postulated that older patients may instead benefit more from antiangiogenic agents. These hypotheses were initially based on preclinical evidence showing different tumor neovascularization 
[42] and a more pronounced inhibitory effect of antiangiogenic treatment [43] in older than in younger xenograft tumor models. Nonetheless, in the present study, despite a trend toward a higher response rate in the elderly, no statistically significant difference in treatment outcomes between young and elderly patients was found.

On crosstrial comparison, the survival outcomes reported in the present study apparently fell short of those achieved in two pivotal phase III trials evaluating sorafenib for HCC. The median OS duration in our cohort was 5.22 months (95\% CI, 4.44-6.05 months), whereas in the sorafenib arm of the Asia Pacific and SHARP (Sorafenib Hepatocellular Carcinoma Assessment Randomized Protocol) trials OS times were 6.5 months [44] and 10.7 months [45], respectively. This observation may be explained by a difference in patient characteristics, such as the inclusion of Child-Pugh class B and ECOG performance status score 2 patients in the current study.

The current study has several limitations. It is a retrospective study involving a relatively limited sample size in the elderly cohort. Comparative arms consisting of younger and older patients who received best supportive care alone or conventional chemotherapy were not included in this study, but such a study design may be associated with ethical concerns now that sorafenib has been established as the standard treatment for advanced HCC [13]. It is worthwhile to note that the results of the current study only demonstrate the efficacy and safety of sorafenib in elderly patients with high functioning status and satisfactory medical conditions, and thus our results cannot be extrapolated to the general elderly advanced HCC population. Our present results highlight the fact that only about half of the elderly advanced HCC population receives sorafenib treatment for advanced HCC and a significant proportion of elderly patients refuse treatment, mainly because of a fear of treatment-related toxicities. Thus, adequate patient education and counseling prior to the start of sorafenib might alleviate unnecessary misconceptions about sorafenib-related toxicities among elderly patients. Last, but not least, a detailed multidimensional geriatric assessment [46], such as scoring of comorbidity levels by validated scales and evaluation of basic and instrumental activities of daily living, was not performed in our elderly cohort. On the other hand, we used the ECOG performance status score, which is a key tool in functional assessment.

In conclusion, the present study is the first to demonstrate the efficacy and tolerability of sorafenib in elderly HCC patients. Although it supports the use of sorafenib in these patients with reasonable liver function and a good performance status, close monitoring for a potentially higher incidence of AEs is warranted. Dedicated prospective studies involving a more substantial number of elderly patients, especially those at the extremes of age or with multiple comorbidities, with detailed evaluation of patients' biological instead of chronological age, are necessary to confirm our findings.

\section{Author Contributions}

Conception/Design: Thomas Yau, Hilda Wong, Tzy-Jyun Yao, Ronnie Poon, Sheung-Tat Fan

Provision of study material or patients: Thomas Yau, Hilda Wong, Joanne Chiu, Roland Leung, Pierre Chan, Tan To Cheung, Albert C. Chan, Ronnie Poon, Sheung-Tat Fan

Collection and/or assembly of data: Thomas Yau, Hilda Wong, Yuen Fong Tang, Tzy-Jyun Yao, Joanne Chiu, Roland Leung, Pierre Chan, Tan To Cheung, Albert C. Chan, Roberta W. Pang, Ronnie Poon, Sheung-Tat Fan

Data analysis and interpretation: Thomas Yau, Hilda Wong, Yuen Fong Tang, Tzy-Jyun Yao, Joanne Chiu, Roland Leung, Pierre Chan, Tan To Cheung, Albert C. Chan, Roberta W. Pang, Ronnie Poon, Sheung-Tat Fan

Manuscript writing: Thomas Yau, Hilda Wong, Yuen Fong Tang, Tzy-Jyun Yao, Joanne Chiu, Roland Leung, Pierre Chan, Tan To Cheung, Roberta W. Pang, Ronnie Poon, Sheung-Tat Fan

Final approval of manuscript: Thomas Yau, Hilda Wong, Yuen Fong Tang, Tzy-Jyun Yao, Joanne Chiu, Roland Leung, Pierre Chan, Tan To Cheung, Albert C. Chan, Roberta W. Pang, Ronnie Poon, Sheung-Tat Fan

\section{REFERENCES}

1. GLOBOCAN 2008: Cancer Incidence and Mortality Worldwide. International Agency for Research on Cancer, World Health Organization, 2010. Available at http://globocan.iarc.fr, accessed June 3, 2011.

2. Jemal A, Siegel R, Xu J et al. Cancer statistics, 2010. CA Cancer J Clin 2010;60:277-300.

3. Cho SJ, Yoon JH, Hwang SS et al. Do young hepatocellular carcinoma patients with relatively good liver function have poorer outcomes than elderly patients? J Gastroenterol Hepatol 2007;22: 1226-1231.

4. Chiaramonte M, Stroffolini T, Vian A et al. Rate of incidence of hepatocellular carcinoma in patients with compensated viral cirrhosis. Cancer 1999;85:2132-2137.

5. Repetto L, Venturino A, Fratino L et al. Geriatric oncology: A clinical approach to the older patient with cancer. Eur J Cancer 2003;39:870-880.

6. Fentiman IS, Tirelli U, Monfardini S et al. Cancer in the elderly: Why so badly treated? Lancet 1990;335:1020-1022.

7. Hutchins LF, Unger JM, Crowley JJ et al. Underrepresentation of patients 65 years of age or older in cancer-treatment trials. N Engl J Med 1999; 341:2061-2067.

8. Unger JM, Coltman CA Jr, Crowley JJ et al. Impact of the year 2000 Medicare policy change on older patient enrollment to cancer clinical trials J Clin Oncol 2006;24:141-144.

9. Collier JD, Curless R, Bassendine MF et al. Clinical features and prognosis of hepatocellular carcinoma in Britain in relation to age. Age Ageing 1994;23:22-27.

10. Giannini E, Romagnoli $P$, Fasoli $A$ et al. Influence of age on clinical presentation, therapeutic options, and prognosis in anti-HCV positive cirrhotic patients with hepatocellular carcinoma. Age Ageing 2002;31:457-462.

11. Dohmen K, Shirahama M, Shigematsu H et al. Optimal treatment strategy for elderly patients with hepatocellular carcinoma. J Gastroenterol Hepatol 2004; 19:859-865.

12. Poon RT, Fan ST, Lo CM et al. Hepatocellular carcinoma in the elderly: Results of surgical and nonsurgical management. Am J Gastroenterol 1999;94:2460-2466.

13. National Comprehensive Cancer Network Clinical Practice Guidelines in Oncology- Hepatobiliary Cancers, Version 1. 2011. Available at http:// www.nccn.org/professionals/physician_gls/pdf/ hepatobiliary.pdf, accessed June 3, 2011.

14. Bruix J, Sherman M, Llovet JM et al. Clinical management of hepatocellular carcinoma. Conclusions of the Barcelona-2000 EASL conference. European Association for the Study of the Liver. J Hepatol 2001;35:421-430.

15. Therasse P, Arbuck SG, Eisenhauer EA et al. New guidelines to evaluate the response to treatment in solid tumors. European Organization for Research and Treatment of Cancer, National Cancer Institute of the United States, National Cancer Institute of Canada. J Natl Cancer Inst 2000;92: 205-216.

16. Cox DR. Regression models and life tables (with discussion). J R Stat Soc Series B Stat Methodol 1972;34:187-220.

17. Grambsch PM, Therneau TM. Proportional hazards tests and diagnostics based on weighted residuals. Biometrika 1994;81:515-526.

18. Kalbfleisch JD, Prentice RL. The Statistical Analysis of Failure Time Data. New York: Wiley, 1980:1-439.

19. Hainsworth JD, Burris HA 3rd, Yardley DA et al. Weekly docetaxel in the treatment of elderly patients with advanced breast cancer: A Minnie Pearl 
Cancer Research Network phase II trial. J Clin Oncol 2001;19:3500-3505.

20. Del Mastro L, Perrone F, Repetto L et al. Weekly paclitaxel as first-line chemotherapy in elderly advanced breast cancer patients: A phase II study of the Gruppo Italiano di Oncologia Geriatrica (GIOGer). Ann Oncol 2005;16:253258.

21. Feher O, Vodvarka P, Jassem J et al. First-line gemcitabine versus epirubicin in postmenopausal women aged 60 or older with metastatic breast cancer: A multicenter, randomized, phase III study. Ann Oncol 2005;16:899-908.

22. Bajetta E, Procopio G, Celio L et al. Safety and efficacy of two different doses of capecitabine in the treatment of advanced breast cancer in older women. J Clin Oncol 2005;23:2155-2161.

23. Vogel C, O'Rourke M, Winer E et al. Vinorelbine as first-line chemotherapy for advanced breast cancer in women 60 years of age or older. Ann Oncol 1999;10:397-402.

24. The Elderly Lung Cancer Vinorelbine Italian Study Group. Effects of vinorelbine on quality of life and survival of elderly patients with advanced non-small-cell lung cancer. J Natl Cancer Inst 1999;91:66-72.

25. Ricci S, Antonuzzo A, Galli L et al. Gemcitabine monotherapy in elderly patients with advanced non-small cell lung cancer: A multicenter phase II study. Lung Cancer 2000;27:75-80.

26. Martoni A, Di Fabio F, Guaraldi M et al. Prospective phase II study of single-agent gemcitabine in untreated elderly patients with stage IIIB/IV nonsmall-cell lung cancer. Am J Clin Oncol 2001;24: 614-617.

27. Gridelli C, Cigolari S, Gallo C et al. Activity and toxicity of gemcitabine and gemcitabine + vinorelbine in advanced non-small-cell lung cancer elderly patients: Phase II data from the Multicenter Italian Lung Cancer in the Elderly Study (MILES) randomized trial. Lung Cancer 2001;31:277-284.

28. Nakamura Y, Sekine I, Furuse K et al. Retro- spective comparison of toxicity and efficacy in phase II trials of 3-h infusions of paclitaxel for patients 70 years of age or older and patients under 70 years of age. Cancer Chemother Pharmacol 2000; 46:114-118.

29. Sandler A, Gray R, Perry MC et al. Paclitaxelcarboplatin alone or with bevacizumab for nonsmall-cell lung cancer. N Engl J Med 2006;355: $2542-2550$

30. Ebi N, Semba H, Tokunaga SJ et al. A phase II trial of gefitinib monotherapy in chemotherapynaive patients of 75 years or older with advanced non-small cell lung cancer. J Thorac Oncol 2008;3: 1166-1171

31. Wheatley-Price P, Ding K, Seymour L et al. Erlotinib for advanced non-small-cell lung cancer in the elderly: An analysis of the National Cancer Institute of Canada Clinical Trials Group Study BR.21. J Clin Oncol 2008;26:2350-2357.

32. Jackman DM, Yeap BY, Lindeman NI et al. Phase II clinical trial of chemotherapy-naive patients $\geq 70$ years of age treated with erlotinib for advanced non-small-cell lung cancer. J Clin Oncol 2007;25:760-766.

33. Eisen T, Oudard S, Szczylik C et al. Sorafenib for older patients with renal cell carcinoma: Subset analysis from a randomized trial. J Natl Cancer Inst 2008;100:1454-1463.

34. Lenfant C, Chobanian AV, Jones DW et al Seventh report of the Joint National Committee on the Prevention, Detection, Evaluation, and Treatment of High Blood Pressure (JNC 7): Resetting the hypertension sails. Hypertension 2003;41:1178 1179.

35. Maitland ML, Kasza KE, Karrison $T$ et al. Ambulatory monitoring detects sorafenib-induced blood pressure elevations on the first day of treatment. Clin Cancer Res 2009;15:6250-6257.

36. Nichols WW, Nicolini FA, Pepine CJ. Determinants of isolated systolic hypertension in the elderly. J Hypertens Suppl 1992;10:S73-S77.

37. Franklin SS, Gustin W 4th, Wong ND et al.
Hemodynamic patterns of age-related changes in blood pressure. The Framingham Heart Study. Circulation 1997;96:308-315.

38. Humphreys BD, Atkins MB. Rapid development of hypertension by sorafenib: Toxicity or target? Clin Cancer Res 2009;15:5947-5949.

39. Boehm S, Rothermundt C, Hess D et al. Antiangiogenic drugs in oncology: A focus on drug safety and the elderly - a mini-review. Gerontology 2010;56:303-309.

40. Spencer FA, Gore JM, Lessard D et al. Venous thromboembolism in the elderly. A community-based perspective. Thromb Haemost 2008;100:780-788.

41. Qi Y, Dy GK, Nelson D et al. Incidence of bleeding and thrombosis among elderly patients (pts) undergoing systemic chemotherapy in advanced non-small cell lung cancer (NSCLC): An analysis of North Central Cancer Treatment Group (NCCTG) trials. J Clin Oncol 2010;28(15 suppl): e18093.

42. Pili R, Guo Y, Chang J et al. Altered angiogenesis underlying age-dependent changes in tumor growth. J Natl Cancer Inst 1994;86:13031314.

43. Kaptzan T, Skutelsky E, Itzhaki O et al. Efficacy of anti-angiogenic treatment of tumors in old versus young mice. Mech Ageing Dev 2006;127: $398-409$.

44. Cheng AL, Kang YK, Chen Z et al. Efficacy and safety of sorafenib in patients in the Asia-Pacific region with advanced hepatocellular carcinoma: A phase III randomised, double-blind, placebo-controlled trial. Lancet Oncol 2009;10: $25-34$.

45. Llovet JM, Ricci S, Mazzaferro V et al. Sorafenib in advanced hepatocellular carcinoma. N Engl J Med 2008;359:378-390.

46. Basso U, Monfardini S. Multidimensional geriatric evaluation in elderly cancer patients: A practical approach. Eur J Cancer Care (Engl) 2004;13: $424-433$. 